\section{THE SURGICAL ANATOMY OF CORONARY VENOUS RETURN IN HEARTS WITH ISOMERIC ATRIAL APPENDAGES}

Although absence of the coronary sinus is widely recognized in hearts with isomerism of the right atrial appendages, little attention has been paid to the fashion of the venous return from the heart itself. In this study, the arrangement of coronary venous return was investigated in 99 specimens with isomeric right and 49 with isomeric left appendages. In the normal heart, the coronary veins consist of a circumflex component within the atrioventricular groove and longitudinal components on the ventricular mass. The circumflex venous system was seen in 44 hearts with isomerism of left appendages ( $90 \%$ ), but 23 of these hearts lacked the anatomic features of the coronary sinus. Circumflex veins were entirely lacking in the other $10 \%$ of hearts with isomeric left appendages and in all those with isomeric right appendages. In these hearts, longitudinal veins drained independently into the atria in three patterns. The first was a direct connection, with the venous orifice opening between the trabeculations of the atrial wall immediately having crossed the atrioventricular groove. The second was a crooked return, with the vein running an intramural course along the atrioventricular groove. The third was a distant connection, reaching superiorly to the smooth-walled atrial component after running an intramural course. Intramural courses were seen in $19 \%$ of the longitudinal veins, such veins being found in $62 \%$ of all hearts with no circumflex venous system. These findings, which to the best of our knowledge have never previously been recognized in detail, almost certainly have potential surgical significance. (J THORAC CARDIOVASC SURG 1995;110:436-44)

Hideki Uemura, MD, ${ }^{\text {a, b }}$ Siew Yen Ho, PhD, ${ }^{a}$ Robert H. Anderson, MD, ${ }^{\text {a, c, d }}$ William A. Devine, BSc, ${ }^{c}$ Audrey Smith, PhD, ${ }^{\mathrm{d}}$ Tokuko Shinohara, MD, ${ }^{\text {a }}$ Toshikatsu Yagihara, $\mathrm{MD},{ }^{\mathrm{b}}$ and Yasunaru Kawashima, $\mathrm{MD},{ }^{\mathrm{b}}$ London and Liverpool, United Kingdom, Osaka, Japan, and Pittsburgh, $\mathrm{Pa}$.
A though anomalous drainages of the systemic and pulmonary veins are expected in hearts with isomeric atrial appendages (visceral heterotaxy), and the universal absence of the coronary sinus is widely recognized in the setting of isomerism of the

From the National Heart and Lung Institute, London, United Kingdom, ${ }^{a}$ National Cardiovascular Center, Suita, Osaka, Japan, ${ }^{\text {b }}$ Children's Hospital of Pittsburgh, Pittsburgh, Pa., ${ }^{c}$ and the Royal Liverpool Children's Hospital, Liverpool, United Kingdom. ${ }^{\mathbf{d}}$

H.U. is a visiting fellow at the National Heart and Lung Institute from NCVC. R.H.A. is a visiting professor at CHP and RLCH from the National Heart and Lung Institute. They and S.Y.H. are supported by the British Heart Foundation.

Received for publication June 3, 1994.

Accepted for publication Dec. 22, 1994.

Address for reprints: Hideki Uemura, MD, National Heart and Lung Institute, Department of Paediatrics, Dovehouse St., London SW3 6LY, United Kingdom.

Copyright $\mathbb{C} 1995$ by Mosby-Year Book, Inc.

$0022-5223 / 95 \$ 3.00+0 \quad \mathbf{1 2 / 1 / 6 3 3 4 8}$ morphologically right appendages, ${ }^{1-6}$ surprisingly little attention has been directed to the venous drainage from the heart itself. Because the coronary circulation consists of both coronary arterial perfusion and venous drainage, the question remains as to the pattern and sites of venous drainage. These factors are potentially of major importance in light of the increasing numbers of surgical procedures performed in patients with isomerism of the atrial appendages. ${ }^{7-11}$ In this study, therefore, we have examined in detail the connections of the coronary veins to the atrial chambers in a large series of postmortem specimens with isomeric atrial appendages.

\section{Materials and methods}

We investigated 148 hearts, 99 with isomeric right and 49 with isomeric left appendages. To define these two entities, we took into account not only the characteristic shape of the appendages, but also their internal features, particularly the nature of their junctions with the smoothwalled atrial components. Thus the pectinate muscles of the morphologically right appendage extend posteriorly 
Table I. Ventricular morphologic and topologic characteristics of the hearts

\begin{tabular}{|c|c|c|}
\hline & $\begin{array}{l}\text { Isomerism } \\
\text { of right } \\
\text { appendages } \\
\text { (No. of } \\
\text { hearts) }\end{array}$ & $\begin{array}{l}\text { Isomerism } \\
\text { of left } \\
\text { appendages } \\
\text { (No. of } \\
\text { hearts) }\end{array}$ \\
\hline Total & 99 & 49 \\
\hline Balanced ventricles* & 45 & 37 \\
\hline Right-hand topology & 23 & 31 \\
\hline Left-hand topology & 22 & 6 \\
\hline Dominant mRVi & 28 & 7 \\
\hline Rudimentary mLV to left & 19 & 6 \\
\hline Rudimentary mLV to right & 9 & 1 \\
\hline Dominant $\mathrm{mLV} \dagger$ & 21 & 4 \\
\hline Rudimentary mRV to right & 11 & 3 \\
\hline Rudimentary mRV to left & 10 & 1 \\
\hline $\begin{array}{l}\text { Solitary and indeterminate } \\
\text { ventriclet }\end{array}$ & 5 & 1 \\
\hline
\end{tabular}

$m R V$, Morphologically right ventricle; $m L V$, morphologically left ventricle. *With biventricular and ambiguous atrioventricular connections. $\dagger$ With univentricular atrioventricular connection.

around the atrioventricular junction to reach the crux of the heart, originating from the terminal crest in the morphologically right atrium. ${ }^{3,12-14}$ In contrast, the pectinate muscles of the morphologically left appendage are limited within the anterolateral portion of the vestibule of the atrioventricular junction, and the terminal crest is lacking in the morphologically left atrium. The morphologic characteristics of the ventricles and the ventricular topologic features in the hearts studied are listed in Table I.

The course of the coronary veins was detected by macroscopic study of the surface of the ventricular mass and by subsequent careful dissection around the atrioventricular groove. At the same time, the atrial orifices of the veins were identified from the inside of the chambers.

Nomenclature. In the normal heart, as well described by Gross ${ }^{15}$ and by Walmsley, ${ }^{16}$ the coronary venous system is composed of the great, middle, and small cardiac veins, which drain the larger part of the ventricular mass through the coronary sinus, the short cardiac veins on the anterosuperior wall of the right ventricle, and the minimal cardiac veins. The minimal cardiac veins are the so-called veins of Thebesius, and their courses cannot be identified on the surface of ventricular mass, because they commence within the atrial or ventricular mass and drain directly into the atrial or ventricular cavities through tiny orifices. The courses of the other two subsets of veins, in contrast, can usually be seen from the outside of the heart.

In terms of their spatial relations to the heart itself, the overall system of veins can be considered as made up of two components. One is a circumflex component within the atrioventricular groove, and the other is the longitudinal component coursing on the epicardial surface of the ventricular mass (Fig. 1).

The coronary sinus, therefore, is part of the circumflex component, beginning at the junction of the oblique vein of Marshall ${ }^{17}$ with the great cardiac vein, with its commencement usually marked by the venous valve of

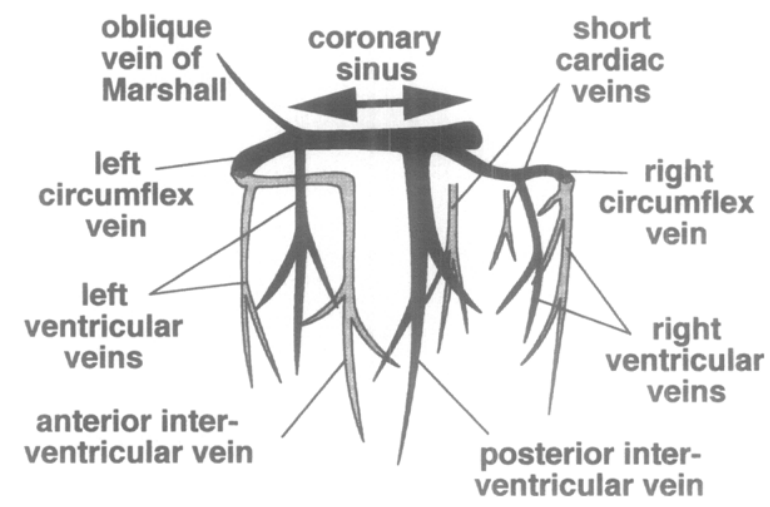

Fig. 1. Coronary veins in the normally structured heart. The diagram is drawn as viewed from behind.

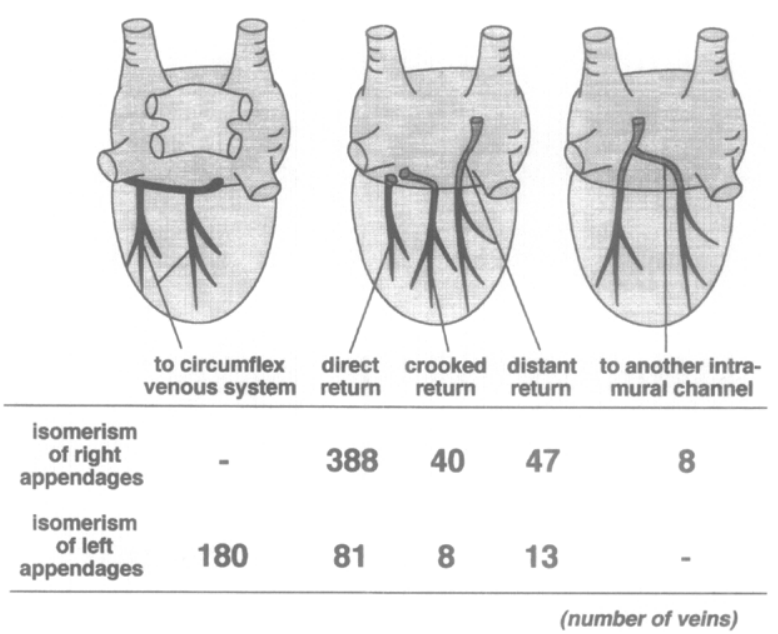

Fig. 2. Overall patterns of drainage of the identified longitudinal veins.

Vieussens. ${ }^{15,16}$ The rest of the circumflex component can be described as the left and the right circumflex veins. The majority of the longitudinal veins are connected to the circumflex venous system in the normal heart. Only a few longitudinal veins, the short cardiac veins, drain directly into the wall of the right atrium on the small area of the right ventricle, where the circumflex system is lacking (Fig. 1). In this study, all the longitudinal veins were described according to the sites of their courses on the surface of the ventricular mass; thus the anterior interventricular veins can be described together with the posterior interventricular veins and the morphologically left ventricular veins with the morphologically right ventricular veins.

\section{Results}

Isomerism of the morphologically right appendages. The coronary sinus was not found in any specimen, nor were any circumflex venous structures identified. 

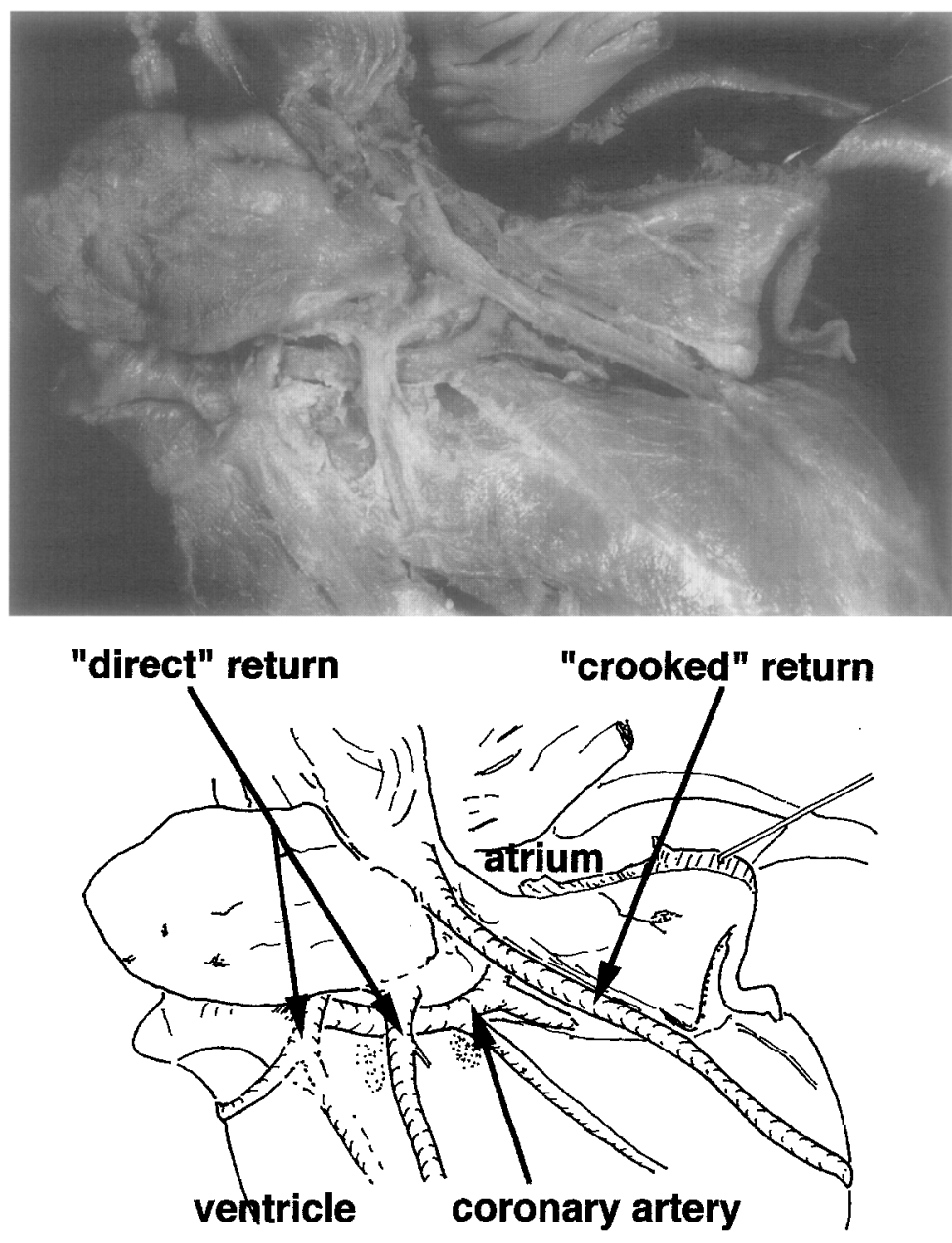

Fig. 3. Direct and crooked venous return. An example in a heart with isomerism of the right appendages. These veins drained through the spaces between the pectinate muscles.

Of the total number of 483 longitudinal veins detected, $475(98 \%)$ drained into the atrium through their own orifices. Three major patterns of drainage were recognized (Fig. 2). In the first pattern, which we called direct drainage, the vein opened through the space between the pectinate muscles after crossing the atrioventricular groove (Fig. 3). In the second pattern, designated as crooked, the vein coursed intramurally along the atrioventricular groove before entering the atrium (Fig. 3). The openings of this type of vein were also through trabeculations between the atrial pectinate muscles. In the third pattern, which we characterized as a distant connection, an extensive intramural course within the atrial wall placed the venous opening remote from the atrioventricular groove (Fig. 4). Such orifices were found in the smooth- walled venous component of the atrium. A total of 47 veins ( $10 \%$ of all 483 veins) with distant return were identified, these being found in 41 hearts ( $41 \%$ of all 99 hearts in this group). An additional 40 veins ( $8 \%$ of veins) were noted to have a crooked return, being seen in 32 hearts $(32 \%$ of hearts). A vein with a crooked connection coexisted with one having distant return in 12 hearts. The remaining eight longitudinal veins did not possess their own orifices. They also possessed intramural courses but joined with an intramural channel of other veins within the atrial wall (see Fig. 2). The veins with distant return were more frequently located at the posterior aspect of the heart than in other quadrants of the atrioventricular junctions, but this tendency was not obvious for other veins with an intramural course (Fig. 5). 

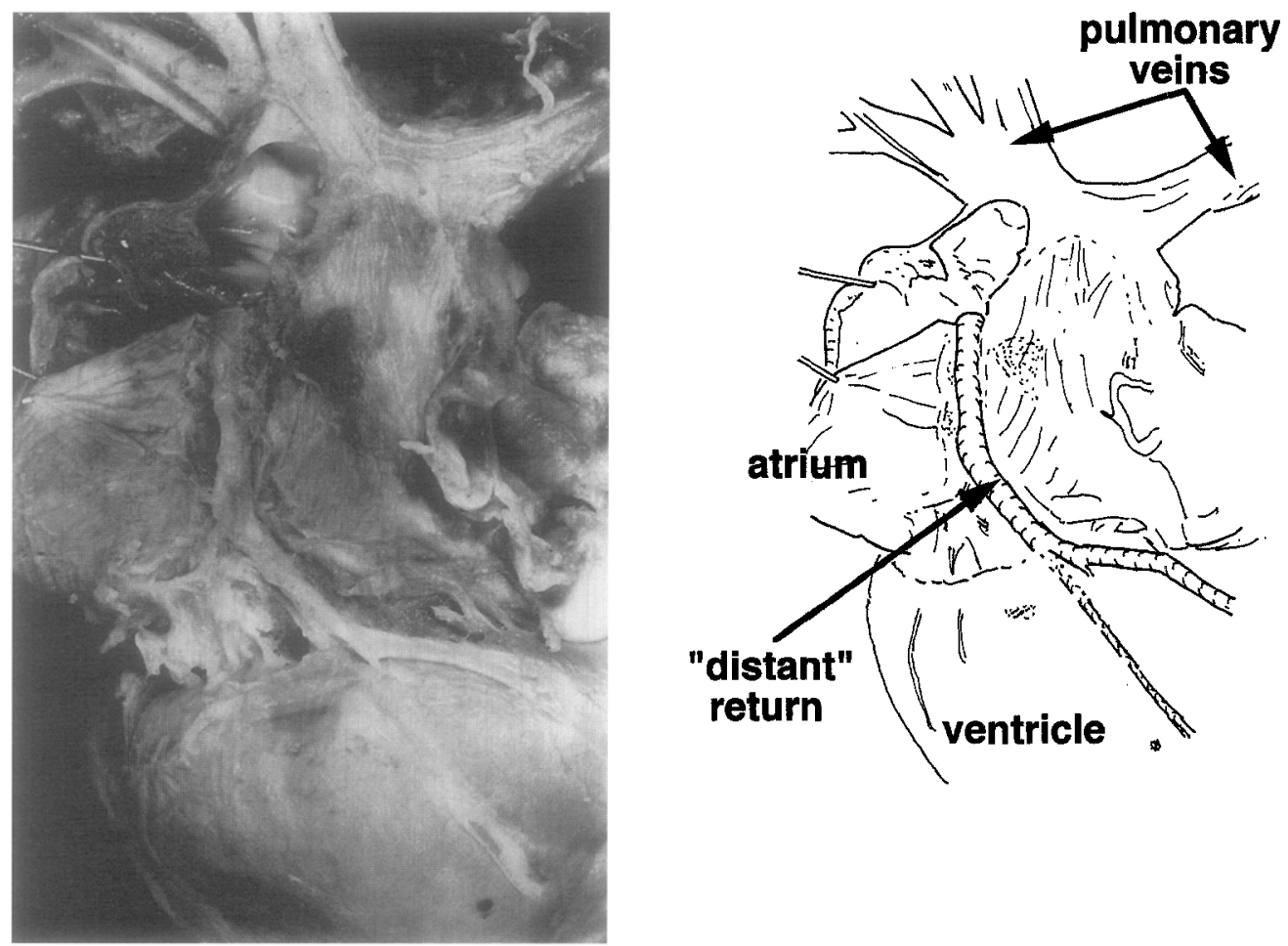

Fig. 4. Distant return seen in another case with isomeric right appendages, with dissection of the intramural course. The venous orifice was located adjacent to the junction of the pulmonary veins with the atrium.

The patterns of drainage of the longitudinal veins according to their morphologic location are shown in Table II. The anterior interventricular vein, when this vein was present, drained to the left-sided appendage of right morphology in 49 hearts with right-hand ventricular topology, and to the rightsided appendage in 37 hearts with left-hand topology. An intramural course was more frequently identified for the posterior interventricular vein and for those veins draining the morphologically left ventricle ( $p=0.003, \chi^{2}$ test). Longitudinal veins were more frequently absent in relation to the morphologically left ventricle when the dominant ventricle was of morphologically right pattern. These veins were lacking in relation to the morphologically right ventricle in hearts having a dominant morphologically left ventricle $\left(p<0.001, \chi^{2}\right.$ test). We failed to positively identify minimal cardiac veins in any specimens.

Isomerism of the morphologically left appendages. Of 49 hearts, $44(90 \%)$ possessed a circumflex component in some part of the atrioventricular junctions, but circumflex veins were lacking com-

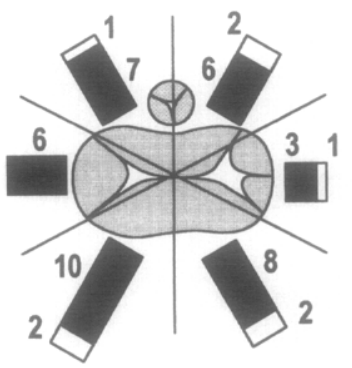

crooked return

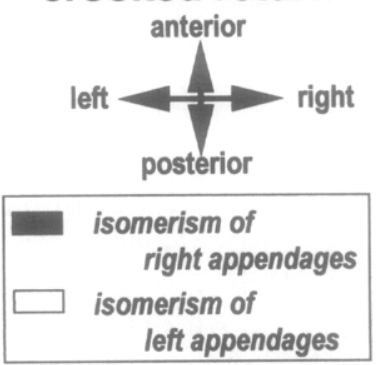

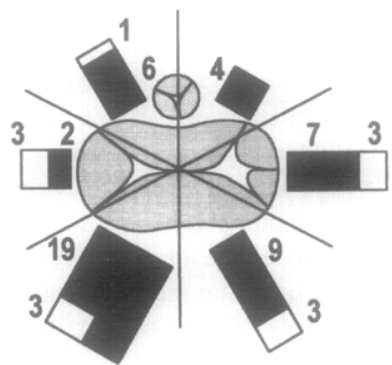

distant return

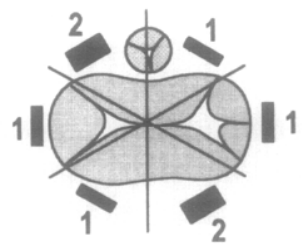

joining into another intramural channel
Fig. 5. Location of the veins having intramural courses. The atrioventricular junction has been divided into three portions, namely the anterior, lateral, and posterior aspects. 
Table II. Longitudinal veins in hearts with isomerism of right appendages*

\begin{tabular}{|c|c|c|c|}
\hline & $\begin{array}{c}\text { By direct } \\
\text { return }\end{array}$ & $\begin{array}{c}\text { Having } \\
\text { intramural } \\
\text { course }\end{array}$ & $\begin{array}{c}\text { Not } \\
\text { identified }\end{array}$ \\
\hline \multicolumn{4}{|l|}{ Anterior interventricular vein } \\
\hline Balanced ventricles & 36 & 7 & 2 \\
\hline Dominant $\mathrm{mRV}$ & 22 & 2 & 4 \\
\hline Dominant $\mathrm{mLV}$ & 16 & 3 & 2 \\
\hline \multicolumn{4}{|l|}{ Posterior interventricular vein } \\
\hline Balanced ventricles & 28 & 13 & 4 \\
\hline Dominant $\mathrm{mRV}$ & 16 & 10 & 2 \\
\hline \multirow[t]{2}{*}{ Dominant $\mathrm{mLV}$} & 17 & 3 & 1 \\
\hline & $\begin{array}{c}\text { All by direct } \\
\text { return }\end{array}$ & $\begin{array}{c}\text { Intramural } \\
\text { course detected }\end{array}$ & $\begin{array}{l}\text { No veins } \\
\text { identified }\end{array}$ \\
\hline \multicolumn{4}{|l|}{ Morphologically left ventricular veins } \\
\hline Balanced ventricles & 29 & 15 & 1 \\
\hline Dominant $\mathrm{mRV}$ & 10 & 4 & 14 \\
\hline Dominant $\mathrm{mLV}$ & 10 & 11 & - \\
\hline \multicolumn{4}{|l|}{ Morphologically right ventricular veins } \\
\hline Balanced ventricles & 29 & 14 & 2 \\
\hline Dominant $\mathrm{mRV}$ & 25 & 3 & - \\
\hline \multirow[t]{2}{*}{ Dominant $\mathrm{mLV}$} & 6 & - & 15 \\
\hline & $\begin{array}{c}\text { All by direct } \\
\text { retum }\end{array}$ & $\begin{array}{c}\text { Intramural } \\
\text { course detected }\end{array}$ & \\
\hline Solitary and indeterminate ventricle & 2 & 3 & \\
\hline
\end{tabular}

For abbreviations see Table I.

*Figures indicate number of hearts.

Table III. Circumflex venous system in hearts with isomerism of left appendages

\begin{tabular}{lc}
\hline Circumflex venous system absent & 5 \\
Circumflex venous system present & 44 \\
Coronary sinus absent & 23 \\
Dual circumflex veins & 11 \\
A solitary circumflex vein & 12 \\
Coronary sinus present & 21 \\
Receiving all circumflex veins & 13 \\
Coexisting independent circumflex vein & 4 \\
Receiving no cardiac venous drainage & \\
Independent circumflex veins present & 2 \\
No other circumflex veins & 2 \\
\hline
\end{tabular}

Figures indicate number of hearts.

pletely in the other five (Table III). A coronary sinus receiving all circumflex veins, as seen in the normal heart, was found in $27 \%$ of cases. Isolated and independent circumflex veins, 41 in number, were identified within 29 hearts (59\%). All these veins, however, lacked those anatomic features that permit distinction of the normal coronary sinus (Fig. 6). Their openings were often located within the rightsided (in 17 veins) or the left-sided (in 17) atrium near the crux of the heart. In three hearts, their orifice was seen anteriorly at the junction of the appendage with the venous component of the atrium. The remaining four circumflex veins, before opening to the atrial cavity, possessed an intramural course within the atrial wall similar to that characterized as distant return for the longitudinal veins.

Of all 282 longitudinal veins detected, $64 \%$ drained via the circumflex venous system. Veins with an intramural course, this feature comparable with that seen in the hearts with isomeric right appendages, were detected in 11 hearts having a circumflex venous system ( $25 \%$ of 44 cases) and also in three with no such circumflex veins ( $60 \%$ of five).

The patterns of drainage for the longitudinal veins are shown in Table IV. The anterior interventricular vein, identified in 46 hearts, drained into the left-sided appendage (in 19) or via the left-sided circumflex vein (in 20) when the ventricular topology was right handed, and into the right-sided appendage in seven cases with left-hand ventricular topology. Absence of the longitudinal veins was related to the rudimentary and incomplete nature of ventricles as, in the group of hearts with isomeric right appendages ( $p<0.001, \chi^{2}$ test). Again, it did not prove possible to detect any minimal cardiac 

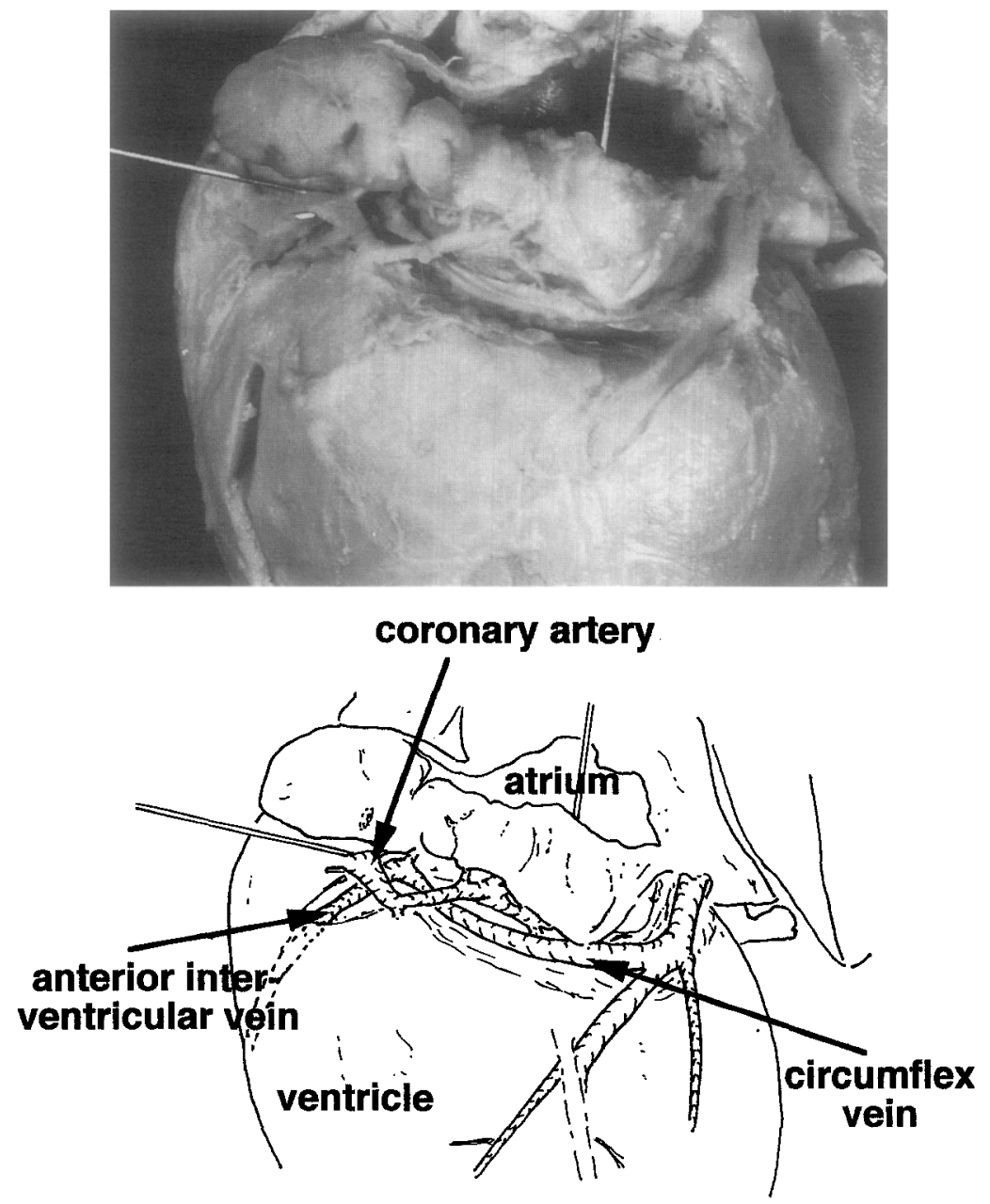

Fig. 6. A circumflex vein seen in a heart with isomerism of the left appendages. Neither an oblique vein of Marshall nor venous valves were found in this particular example, which suggests that it was not a true coronary sinus. The orifice of this circumflex vein was located within the left-sided atrial chamber.

veins draining to the atrial or ventricular chambers in any specimen with isomeric left appendages.

\section{Discussion}

Relatively few descriptions have been given for the anatomy of the coronary veins, even in the normal heart. ${ }^{15,16,18,19}$ For hearts with isomeric atrial appendages, previous information concerning coronary venous return has been limited to statements concerning the presence or absence of the coronary sinus. ${ }^{1-6}$ Not only the coronary sinus but also the circumflex venous components within the atrioventricular grooves were deficient in our series of hearts with right isomerism. Even in the group of hearts with isomeric left appendages, the circumflex venous system was not always as complete as is seen in the normal heart. Thus it is unusual to find one or more isolated circumflex veins independent of the coronary sinus in a normal heart. The diameter of such circumflex veins in the abnormal hearts gave us the impression that these venous structures are somehow insufficient for draining the majority of the coronary perfusion. The orifices of such circumflex veins were also relatively small.

As can be anticipated from the coronary venous architecture in the normal heart, longitudinal veins are likely to be connected in direct fashion to the atrial wall when circumflex veins are lacking. It was unexpected, however, to encounter such curious intramural courses within the atrial wall as found in our material, particularly when veins with abnormal intramural courses are prevalent. To the best of our 
Table IV. Longitudinal veins in hearts with isomerism of left appendages*

\begin{tabular}{|c|c|c|c|c|}
\hline & $\begin{array}{c}\text { By direct } \\
\text { return }\end{array}$ & $\begin{array}{c}\text { Having } \\
\text { intramural } \\
\text { course }\end{array}$ & $\begin{array}{c}\text { Not } \\
\text { identified }\end{array}$ & $\begin{array}{l}\text { Via circumflex } \\
\text { venous system }\end{array}$ \\
\hline \multicolumn{5}{|c|}{ Anterior interventricular vein } \\
\hline Balanced ventricles & 17 & 2 & 2 & 16 \\
\hline Dominant mRV & 4 & - & - & 3 \\
\hline Dominant mLV & 2 & 1 & - & 1 \\
\hline \multicolumn{5}{|c|}{ Posterior interventricular vein } \\
\hline Balanced ventricles & 8 & 1 & - & 28 \\
\hline Dominant mRV & 1 & - & - & 6 \\
\hline \multirow[t]{2}{*}{ Dominant $\mathrm{mLV}$} & - & 1 & - & 3 \\
\hline & $\begin{array}{l}\text { All by direct } \\
\text { return }\end{array}$ & $\begin{array}{c}\text { Intramural } \\
\text { course detected }\end{array}$ & $\begin{array}{l}\text { No veins } \\
\text { identified }\end{array}$ & $\begin{array}{l}\text { Via circumflex } \\
\text { venous system }\end{array}$ \\
\hline \multicolumn{5}{|c|}{ Morphologically left ventricular veins } \\
\hline Balanced ventricles & 6 & 5 & - & 26 \\
\hline Dominant mRV & 1 & - & 4 & 2 \\
\hline Dominant mLV & 1 & 1 & - & 2 \\
\hline \multicolumn{5}{|c|}{ Morphologically right ventricular veins } \\
\hline Balanced ventricles & 10 & 5 & - & 22 \\
\hline Dominant mRV & - & 2 & - & 5 \\
\hline \multirow[t]{2}{*}{ Dominant $\mathrm{mLV}$} & - & - & 2 & 2 \\
\hline & \multicolumn{2}{|c|}{$\begin{array}{l}\text { Some by direct return and the } \\
\text { others via circumflex system }\end{array}$} & & \\
\hline
\end{tabular}

For abbreviations see Table I.

*Figures indicate number of hearts.

knowledge, no descriptions have previously been made of this abnormality in malformed hearts.

It is one thing to observe such patterns in autopsied hearts. It is quite another matter to recognize these abnormal veins preoperatively in living patients. Angiographic or echocardiographic studies seem unlikely to be adequate at present. Although we have seen one angiographic study in which a longitudinal vein with direct return was visualized by retrograde injection, the insertion of the catheter into its orifice had been incidental. It is unrealistic to expect to insert the tip of the catheter into every orifice of all the major longitudinal veins so as to obtain diagnostic images. Furthermore, we are not convinced that selective coronary arterial injection is of value in revealing precisely the coronary venous system during the venous phase of imaging. It might also be impossible to identify, even during surgery, those venous orifices located near the atrioventricular junction and opening through the trabeculations of the atrial walls. In contrast, those seen in the smooth-walled component of the atrium are readily visible. Some of the orifices for veins with a crooked or direct return can be identified more clearly in hearts with isomeric left than in those with isomeric right appendages, because there are no pectinate muscles at the posterior vestibule of the atrioventricular junction when the appendages are of morphologically left pattern. Orifices for longitudinal veins having a distant return are often located at the lateral side of the area of pulmonary venous connection to the atrium or at sites adjacent to a hepatic venous connection. In other words, the margins of the venous components of the atrial chambers require careful inspection to ascertain the site of the drainage of the intramural course of distant veins before intraatrial surgical maneuvers. Such features would almost certainly be overlooked by the surgeon who had no prior knowledge of the abnormalities.

It is self-evidently important to know precisely these abnormalities in the coronary veins so as to minimize damage to them. In fact, among the 148 hearts in our present study, several specimens showed obstruction of the coronary veins as a consequence of previous surgical operations. Thus, in three hearts with isomeric right appendages, intramural courses of the longitudinal veins with the distant return had been incised and sutured, which resulted in complete occlusion of the veins. In another two hearts with isomeric left appendages, 
subsequent to intraatrial rerouting by means of a heterologous pericardial baffle, the suture line passed beside the orifices of the circumflex veins and produced severe orificial stenosis. It would surely have been feasible to avoid occlusions of these veins during surgical procedures had their ectopic openings in the atria been appreciated. The orificial obstruction, nonetheless, can be produced not only by intraatrial surgical maneuvers, but also by postoperative formation of intraatrial thrombus. ${ }^{20}$ In particular, the openings of the longitudinal veins through the spaces between the pectinate muscles could readily be occluded by widespread thrombosis. In one of our patients in Osaka, who died of ventricular dysfunction and regurgitation of a common atrioventricular valve 6 months after total cavopulmonary connection, most of the coronary venous orifices were occluded by extensive and organized thrombi.

In addition to these possibilities of mechanical obstructions, the functional influence of atrial pressures on the coronary circulation after the operation should also be taken into consideration. In the setting of the Fontan circulation, for example, two compartments are produced after surgery with markedly different venous pressures. If total cavopulmonary connection is achieved with a tube graft, ${ }^{8,21}$ all coronary venous drainages will then be into the atrium, which is at low pressure (Fig. 7). In contrast, after a conventional Fontan operation, ${ }^{22}$ or one of its modifications in which flow from the inferior caval vein is directed to the pulmonary arteries through the partitioned atrial chamber, ${ }^{8,23}$ some of the coronary veins might drain into the high-pressure chamber and others into the lowpressure one (Fig. 7). Such partially different pressures within the coronary veins can produce an "unbalanced" coronary circulation, with the ensuing possibility of partial myocardial dysfunction. In this respect, therefore, total cavopulmonary connection might be an advantageous option over the atriopulmonary connection for surgical repair in hearts with isomeric atrial appendages. Although the concept of the unfavorable effect of an "unbalanced" coronary circulation has yet to be proved, it may well have important clinical consequences in the context of the effect of elevated coronary venous pressure on ventricular function after the Fontan operation. 25

All these clinical implications remain speculative. Drainage via collateral channels can develop in the systemic venous system when a certain vein is occluded. It is probable that coronary venous drainage will also be redirected via alternative pathways after

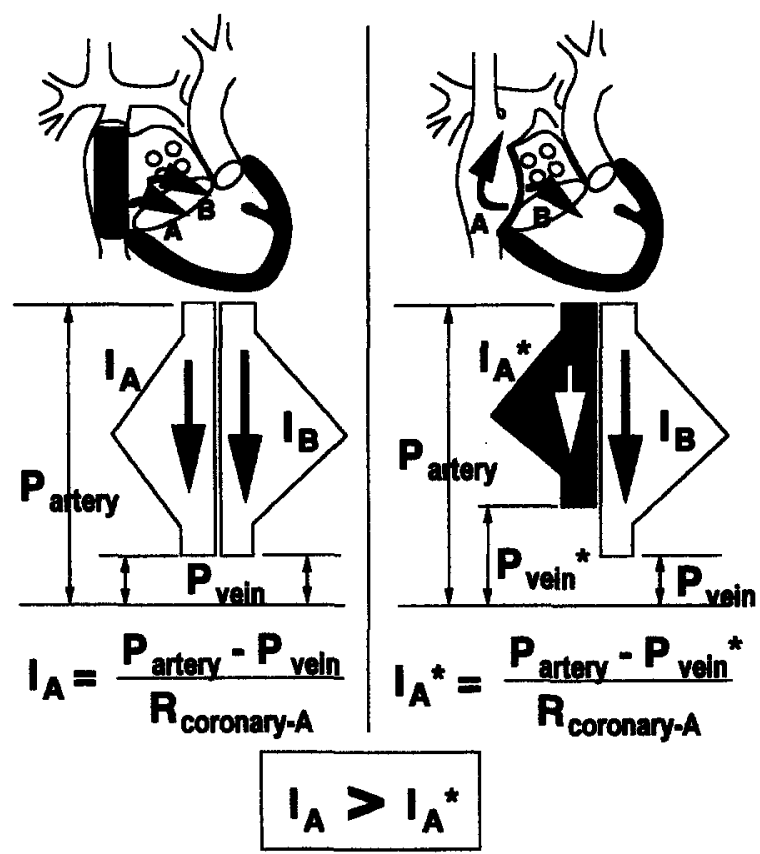

$P$ : pressure $R$ : resistance $I$ : amount of flow

Fig. 7. Theoretically possible influence of unequal pressures in the coronary veins on coronary perfusion.

obstructions of the coronary veins. The practical influence of impaired coronary venous drainage, therefore, is equivocal. Problems in this venous system, nonetheless, could be of clinical significance, in particular immediately after extensive or radical operations. The diminution of myocardial edema is unlikely to worsen the postoperative condition. Once anatomic information is appreciated concerning the coronary venous system, it will not be necessary to jeopardize the coronary veins and thus impair the coronary circulation. Our present study provides this much-needed information.

To integrate the understanding of the entire system of the coronary veins, however, requires further investigations. The minimal cardiac veins, for instance, could not be identified in this study, presumably because of our chosen macroscopic method of investigation. The smallest veins we were able to identify on the surface of hearts were probably $0.2 \mathrm{~mm}$ in diameter. Such minute structures could not be traced within the musculature of the heart. The tiny orifices of the minimal veins also were impossible to identify. Particularly in the setting of bilaterally right appendages, the well-developed pectinate muscles cover the larger parts of the internal surfaces of the atrial chambers. ${ }^{14}$ These features make it difficult to 
identify the venous orifices, even of relatively large vessels. Some other method, such as microscopic or angiographic techniques, might make it feasible in the future to demonstrate the detailed structures of the entire coronary venous and lymphatic systems. We are confident, nonetheless, that our presently described macroscopic findings will be of immediate help for future surgical management.

\section{REFERENCES}

1. Kirklin JW, Barratt-Boyes BG. Atrial isomerism. In: Kirklin JW, Barratt-Boyes BG, eds. Cardiac surgery, 2nd ed, Vol 2. New York: Churchill Livingstone, 1993:1585-96.

2. Macartney FJ, Zuberbuhler JR, Anderson RH. Morphological considerations pertaining to recognition of atrial isomerism: consequences for sequential chamber localization. Br Heart J 1980;44:657-67.

3. Ho SY, Cook A, Anderson RH, Allan LD, Fagg N. Isomerism of the atrial appendages in the fetus. Pediatr Pathol 1991;11:589-608.

4. Van Mierop LHS, Wiglesworth FW. Isomerism of the cardiac atria in the asplenia syndrome. Lab Invest 1962;11:1303-15.

5. Van Mierop LHS, Gessner IH, Schiebler GL. Asplenia and polysplenia syndrome. In: Birth defects: original article series, Vol VIII, No 1. 1972:74-82.

6. Anderson RH, Macartney FJ, Shinebourne EA, Tynan M, Sapire DW. Atrial isomerism. In: Anderson RH, Macartney FJ, Shinebourne EA, Tynan M, eds. Paediatric cardiology, Vol 1. London: Churchill Livingstone, 1987:473-95.

7. Kawashima Y, Matsuda H, Naito Y, Yagihara T, Kadoba K, Matsuki O. Biventricular repair of cardiac isomerism with common atrioventricular canal with the aid of an endocardial cushion prosthesis. J THORAC CARDIOVASC SuRg 1993;106:248-54.

8. Humes RA, Feldt RH, Porter CJ, Julsrud PR, Puga FJ, Danielson GK. The modified Fontan operation for asplenia and polysplenia syndrome. J THORAC Cardiovasc Surg 1988;96:212-8.

9. Kawashima Y, Kitamura S, Matsuda H, Shimazaki Y, Nakano S, Hirose $H$. Total cavopulmonary shunt operation in complex cardiac anomalies: a new operation. J Thorac Cardiovasc Surg 1984;87:74-81.

10. Pacifico AD, Ricchi A, Bargeron LM Jr, Colvin EC, Kirklin JW, Kirklin JK. Corrective repair of complete atrioventricular canal defects and major associated cardiac anomalies. Ann Thorac Surg 1988;46:645-51.

11. Driscoll DJ, Offord KP, Feldt RH, Schaff HV, Puga FJ, Danielson GK. Five- to fifteen-year follow-up after Fontan operation. Circulation 1992;85:469-96.

12. Anderson RH, Becker AE, Freedom RM, et al. Sequential segmental analysis of congenital heart disease. Pediatr Cardiol 1984;5:281-5.
13. Sharma S, Devine W, Anderson RH, Zuberbuhler JR. The determination of atrial arrangement by examination of appendage morphology in 1842 heart specimens. Br Heart J 1988;60:227-31.

14. Anderson RH, Becker AE. The atrial chambers and ventricles: anomalies of atrial arrangement. In: Anderson RH, Becker AE, eds. The heart. London: Gower Medical Publishing, 1992:6.1-6.6.

15. Gross L. The veins of the heart. In: Gross L, ed. The blood supply to the heart. New York: Paul B Hoeber, 1921:93-104.

16. Walmsley T. Blood vessels of the heart. In: SharpeySchafer E, Symington J, Bryce TH, eds. Quain's elements of anatomy, 11th ed, Vol IV, part III, The heart. London: Longmans Green, 1929:98-109.

17. Marshall J. On the development of the great anterior veins in man and mammalia; including an account of certain remnants of faetal structure found in the adult, a comparative view of these great veins in the different mammalia, and an analysis of their occasional peculiarities in the human subject. In: Philosophical transactions. 1849:133-70.

18. Anderson RH, Becker AE. Cardiac anatomy: the coronary veins. In: Anderson RH, Becker AE, eds. The heart. London: Gower Medical Publishing, 1992:1.36.

19. Wilcox BR, Anderson RH. Surgical anatomy of the coronary circulation: the coronary veins. In: Wilcox BR, Anderson RH, eds. Surgical anatomy of the heart, 2nd ed. London: Gower Medical Publishing, 1992:4.7-4.8.

20. Hedrick M, Elkins RC, Knott-Craig CJ, Razook JD. Successful thrombectomy for thrombosis of the right side of the heart after the Fontan operation: report of two cases and review of the literature. J THORAC CARDiovasc Surg 1993;105:297-301.

21. de Leval MR, Kilner P, Gewillig M, Bull C. Total cavopulmonary connection: a logical alternative to atriopulmonary connection for complex Fontan operations-experimental studies and early clinical experience. J Thorac Cardiovasc Surg 1988;96:682-95.

22. Fontan F, Baudet E. Surgical repair of tricuspid atresia. Thorax 1971;26:240-8.

23. Doty DB, Marvin WJ, Lauer RM. Modified Fontan procedure: methods to achieve direct anastomosis of right atrium to pulmonary artery. J THORAC CARDIOVASC SURG 1981;81:470-5.

24. Ilbawi MN, Idriss FS, Muster AJ, et al. Effects of elevated coronary sinus pressure on left ventricular function after Fontan operation: an experimental and clinical correlation. J THORAC Cardiovasc SuRG 1986;92:231-7.

25. Miura T, Hiramatsu T, Forbess JM, Mayer JE Jr. Effects of elevated coronary sinus pressure on coronary blood flow and left ventricular function: implications after Fontan operation [Abstract]. Circulation 1994;90(Suppl):1420. 